\title{
A New Minimally Invasive Mesotherapy Technique for Facial Rejuvenation
}

\author{
Antonella Savoia $\cdot$ Simone Landi $\cdot$ Alfonso Baldi
}

To view enhanced content go to www.dermtherapy-open.com Received: October 19, 2012 / Published online: January 8, 2013

(c) The Author(s) 2013. This article is published with open access at Springerlink.com

\section{ABSTRACT}

Introduction: This study describes a pivotal clinical trial of a new minimally invasive mesotherapy technique for facial rejuvenation.

Methods: The authors utilized two formulations: formulation A with hyaluronic acid, vitamins, amino acids, minerals, coenzymes, and antioxidant substances; formulation B with hyaluronic acid and idebenone. Fifty participants were enrolled in the study and divided in two groups. Group 1 (50-65 years) treated with formulation A. Group 2 (35-50 years) treated with formulation $B$. The groups underwent four sessions of mesotherapy involving multiple injections. Treatment was

A. Savoia · S. Landi

Promoitalia Group S.p.A, Pozzuoli, Naples, Italy

A. Baldi $(\square)$

Department of Biochemistry, Sect. Pathology, Second University of Naples, Via L. Armanni 5, 80138 Naples, Italy

e-mail: alfonsobaldi@tiscali.it

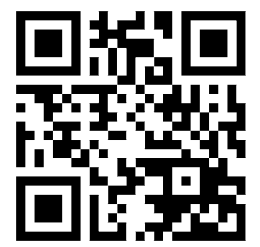

Enhanced content for this article is available on the journal web site:

www.dermtherapy-open.com conducted at 15 day intervals. All participants had pre- and posttreatment photographs. Punch biopsies were taken from randomly selected participants, baseline and after 6 weeks, and stained for interleukin (IL)-6, IL$1 \beta$, matrix metalloproteinase (MMP)-1, and collagen 1. Clinical evaluation was based on the Global Aesthetic Scale (GAIS) and on the Wrinkle Severity Rating Scale (WSRS).

Results: The results produced were statistically analyzed and resulted in a significant and long-lasting effect on facial rejuvenation. Evaluation of photographs at 0,1 , and 2 months revealed significant clinical improvement: brightness, texture, and firmness of the skin. The analysis of the GAIS and WSRS scores in the two groups demonstrated statistically significant results after 2 months. The biopsies taken from randomly selected participants at baseline and after 3 months showed a decrease in IL$1 \beta$, IL-6, and MMP1, and an increase in collagen 1 .

Conclusion: The new minimally invasive mesotherapy technique described can improve the clinical appearance of the skin in different age groups. 
Keywords: Biorevitalization;

Cosmetic dermatology; Facial rejuvenation; Fillers; Mesotherapy; Soft-tissue augmentation

\section{INTRODUCTION}

Aging is an increasing concern of modern society, particularly aging of the face. This is a complex process involving two important factors: volume loss throughout the face, and repetitive muscle movements that cause wrinkles and folds [1]. Traditionally, facial rejuvenation has focused on various dermatologic cosmetic procedures such as carbon dioxide laser resurfacing, microdermabrasion, and electric stimulation leading to collagen production in human skin fibroblasts [2,3]. In recent years there has been an increasing emphasis on mesotherapy as an anti-aging strategy. Mesotherapy is a medical procedure introduced by Pistor in 1958, which consists of intradermal injection of pharmacologic substances, such as nutrients, hormones, vitamins, enzymes, and other reagents that have been diluted and are administered directly into the region to be treated [4]. The aim of mesotherapy in skin rejuvenation is maintenance and/or restoration of healthy and youthful texture of the skin [5, 6]. The desired final effect is firm, bright, moisturized skin obtained by the injection in the superficial dermis of suitable products that are perfectly biocompatible and totally absorbable [7]. In fact, injection of mesotherapy products promotes skin rejuvenation by increasing both hydration and fibroblast activation $[8,9]$. Several experimental studies have demonstrated that hyaluronic acid injected into the skin can stimulate fibroblasts to express collagen type 1 (Col-1), matrix metalloprotease-1 (MMP-1), and tissue inhibitor of matrix metalloproteinase-1 (TIMP) [10]. Another study suggested that dermal injection of vitamins results in stimulation of collagen production in skin cells [11]. It is also well known that antioxidant substances are able to reverse aging. One the most studied hypotheses regarding aging is that it is caused by oxidative stress, and oxidation can damage proteins, DNA, and lipids.

The present study describes a pivotal comparative clinical study of a minimally invasive technique of skin rejuvenation consisting of multiple intradermal injections with two formulations with the goal of maintenance and/or restoration of healthy and youthful skin texture.

\section{MATERIALS AND METHODS}

In this clinical study two different formulations were used: formulation A, which was composed of hyaluronic acid, vitamins, amino acids, minerals, coenzymes, and antioxidants (Table 1), and formulation B, which was composed of hyaluronic acid, idebenone, polysorbate 20, water, acetyl cysteine, sodium chloride.

\section{Patients}

Fifty healthy patients of both genders were enrolled in the study and were divided into two groups: group 1 (32 patients), aged between 50 and 60 years (older patients) and group 2 (18 patients), aged between 35 and 50 years (younger patients). Formulation A was used for patients in group 1 and formulation $B$ was used for patients in group 2. Exclusion criteria for the study were: patients that had undergone other medical-aesthetical treatments, and pregnant or breastfeeding women. Inclusion criteria were: 
Table 1 Characteristics of formulation A

\begin{tabular}{|c|c|c|c|c|c|}
\hline Vitamins & Amino acids & Minerals & Nucleotides & Coenzymes & Others \\
\hline Tocopherol & Arginine & Sodium chloride & Adenine & Inositol & Sodium hyaluronate \\
\hline Ubiquinone & Lysine & & Cytosine & Acetyl cysteine & Water \\
\hline Cyanocobalamin & Isoleucine & & Glutamine & & Polysorbate 20 \\
\hline Folic acid & Leucine & & Guanine & & \\
\hline Riboflavin & Threonine & & & & \\
\hline Pyridoxine HCL & Valine & & & & \\
\hline Thiamine HCL & Histidine hydrochloride & & & & \\
\hline Nicotinamide & Tyrosine & & & & \\
\hline Calcium pantothenate & Phenylalanine & & & & \\
\hline \multirow[t]{10}{*}{ Ascorbic acid } & Glutamic acid & & & & \\
\hline & Aspartic acid & & & & \\
\hline & Asparagine & & & & \\
\hline & Cysteine & & & & \\
\hline & Proline & & & & \\
\hline & Serine & & & & \\
\hline & Alanine & & & & \\
\hline & Methionine & & & & \\
\hline & Glycine & & & & \\
\hline & Tryptophan & & & & \\
\hline
\end{tabular}

HCL hydrochloride

patients in good health, patients that were not using any other treatments, and patients that presented mild/moderate to severe photo-aging. The patients did not modify their lifestyle. All patients gave written consent for enrollment into the clinical study, and ethical approval was obtained for the study.

\section{Treatment and Evaluation Protocol}

Each treatment was carried out according to a default protocol, which was similar for the two groups. Briefly, all participants underwent four sessions of mesotherapy involving multiple injections with a $30 \mathrm{G} / 4 \mathrm{~mm}$ needle in the face, neck, and décolleté. The hands of eight patients were additionally treated. Treatments were conducted over 2 months. The objective examination was carried out with inspection using a Wood's light (GIMA S.p.A., Gessate, Milano, Italy) and palpation to verify cutaneous elasticity. The areas of the body treated were examined by the sense of touch and pressure. The results were defined with a score derived from the Global Aesthetic Improvement Scale (GAIS), used as a reference parameter (Table 2); a summary of the patients' characteristics and of GAIS scores obtained is provided in Table 3. The photographic evaluation was performed at the beginning and at the end of the treatment. 
Table 2 Global aesthetic improvement scale

\begin{tabular}{|c|c|c|}
\hline & Degree & Description \\
\hline 1 & $\begin{array}{l}\text { Exceptional } \\
\text { improvement }\end{array}$ & Excellent corrective result after a session with the Spherofill device \\
\hline 2 & $\begin{array}{l}\text { Very improved } \\
\text { patient }\end{array}$ & $\begin{array}{l}\text { Marked improvment of the appearance, but not completely optimal. A touch-up would slightly } \\
\text { improve the result }\end{array}$ \\
\hline 3 & Improved patient & $\begin{array}{l}\text { Improvement of the appearance, better compared to the initial condition, but a touch-up is } \\
\text { advised }\end{array}$ \\
\hline 4 & Unaltered patient & The appearance substantially remains the same compared to the original condition \\
\hline 5 & Worsened patient & The appearance has worsened compared to the original condition \\
\hline
\end{tabular}

Table 3 Wrinkle severity rating scale

\begin{tabular}{ll}
\hline Score & Description \\
\hline 1 & Absent \\
2 & Slight \\
3 & Moderate \\
4 & Severe \\
5 & Extreme \\
\hline
\end{tabular}

Moreover, the Wrinkle Severity Rating Scale (WSRS) was also used to evaluate the condition of the wrinkles and, therefore, the degree of aging.

\section{Histology and Immunohistochemistry}

Punch biopsies were taken from randomly selected participants at baseline and after 6 weeks. Excised tissue samples were transferred in $4 \%(\mathrm{~m} / \mathrm{v})$ paraformaldehyde solution and were paraffin embedded. Sections of $5 \mu \mathrm{m}$ were stained with hematoxylin-eosin, hematoxylin-Van Gieson, and Periodic acidSchiff (PAS)-Alcian blue hematoxylin (Carlo Erba, Milano, Italy). For immunohistochemistry, tissue sections were heated twice in a microwave oven for $5 \mathrm{~min}$ each at $700 \mathrm{~W}$ in citrate buffer $(\mathrm{pH}$ 6.0). Slides were then incubated at $4{ }^{\circ} \mathrm{C}$ overnight at $1: 100$ dilution with the following antibodies: mouse monoclonal to interleukin-1 $\beta$ (IL-1 $\beta$ ) (AbD Serotec, Oxford, UK); mouse monoclonal to IL6 (Origene, MD, USA); mouse monoclonal to MMP1 (Santa Cruz, CA, USA); and rabbit polyclonal to Col-1 (Santa Cruz, CA, USA). After three washes in phosphate-buffered saline (PBS) to remove the excess antiserum, the slides were incubated with diluted goat antirabbit or anti-mouse biotinylated antibody (Vector Laboratories, Burlingame, CA, USA) at 1:200 dilution in PBS-3\% nonfat dry milk for $1 \mathrm{~h}$. All the slides were then processed by the avidin-biotin complex (ABC) method (Vector Laboratories, Burlingame, CA, USA) for $30 \mathrm{~min}$ at room temperature. The $\mathrm{ABC}$ method relies on the strong affinity of avidin or streptavidin for the vitamin, biotin, for the revelation of the immune complex formed on a tissue by an antigen and a specific antibody raised against this antigen. Diaminobenzidine was used as the final chromogen and hematoxylin was used as the nuclear counter stain. Negative controls for each tissue section were prepared by leaving out the primary antiserum. All samples were processed under the same conditions. The intensity of expression per field $(20 \times$ original magnification) using light microscopy was 
calculated and compared in different specimens by two separate observers (A.B. and A.S.) in a double-blind fashion and described as: score 0 (absent); score 1 (low); score 2 (moderate); score 3 (intense). On average 22 fields were observed for each specimen. The percentage of concordance between the two observers was 93\% (28 over 30); in the remaining specimens the final score was reached after collegial revision.

\section{Statistical Analysis}

Descriptive analysis was made using median values and 95\% confidence intervals. The differences in the GAIS scores at the different timepoints for each group were performed using Wilcoxon's test for nonparametric dependent continuous variables. Statistical Product and Service Solutions (SPSS) software (version 17.0, SPSS, Chicago, IL, USA) was used for statistical analysis. A $P$ value (two tailed) of less than 0.05 was considered to indicate statistical significance.

\section{RESULTS}

The treatment caused minimum discomfort, without any posttreatment pain. All patients returned to their everyday activities immediately after the treatment. In a small number of patients $(n=15)$ ecchymosis were found; moreover, hyperemia secondary to the traumatic action of the needle and vasoactive substances was reported in 12 patients, but this resolved a few days after the application of an anti-edemigen and anti-inflammatory cream. Edema reactions associated with moderate pain due to pressure after the injections were evident in five patients. On objective examination, both formulations resulted in an improvement in the epidermal texture, and an increase in elasticity and brightness of the skin. The effect of the contraction of collagen and production of new natural collagen was highlighted by the increase in tone and compactness. Such features were appreciable by gently skimming over or touching the skin. These features were evidenced by photographic documentation (Fig. 1). Indeed, the patients was recorded a high degree of satisfaction via the completion of a self-assessment questionnaire. At the end of the trial, the majority of the patients claimed the treated area had improved. The positive treatment response was also confirmed by analysis of the GAIS and WSRS scores. Interestingly, both formulations achieved good results, based on the WSRS score after only 2 weeks of treatment. The results were further ameliorated at the end of the treatment, after 4 weeks. In detail, the GAIS score reached a significant difference after four treatments $(P=0.008)$, whereas the WSRS score was significant after only 2 weeks of

A

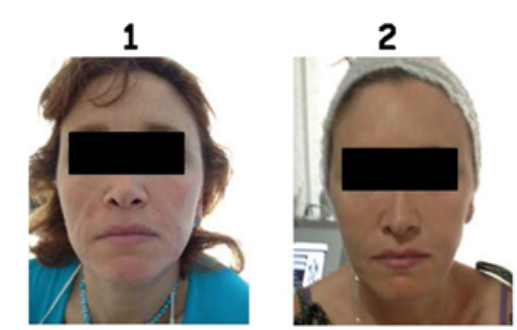

B
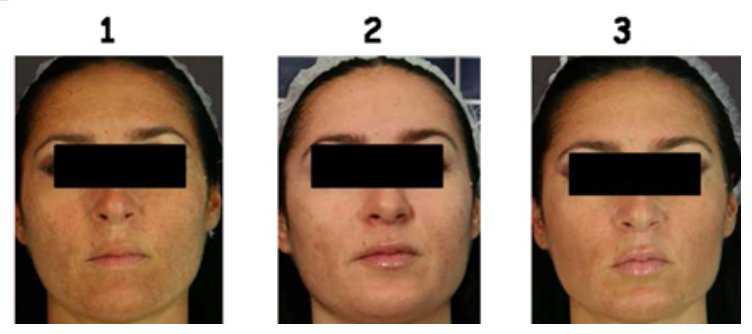

Fig. 1 Example cases of facial rejuvenation in the two different patient groups. a A female patient at the beginning of the treatment (1) and at the end of the treatment with formulation A (2). b A female patient at the beginning of the treatment (1), after one session (2), and at the end of the treatment with formulation $\mathrm{B}$ 
Table 4 Characteristics of the patients enrolled in the study

\begin{tabular}{|c|c|c|c|c|c|c|c|c|c|}
\hline No. & Sex & Age (years) & Formulation used & Treatment site & GAIS1 & GAIS2 & WSRSO & WSRS1 & WSRS2 \\
\hline 1 & $\mathrm{~F}$ & 52 & A & Face/neck & 1 & 1 & 4 & 3 & 3 \\
\hline 2 & M & 55 & A & Face/neck & 1 & 1 & 3 & 2 & 2 \\
\hline 3 & $\mathrm{~F}$ & 64 & A & Face/décolleté & 3 & 2 & 5 & 4 & 4 \\
\hline 4 & M & 56 & A & Face/neck/hands & 2 & 2 & 4 & 4 & 3 \\
\hline 5 & $\mathrm{~F}$ & 53 & A & Face/décolleté & 2 & 1 & 4 & 3 & 2 \\
\hline 6 & M & 60 & A & Face/neck & 4 & 3 & 4 & 3 & 3 \\
\hline 7 & $\mathrm{~F}$ & 59 & A & Face/neck/hands & 4 & 2 & 4 & 4 & 3 \\
\hline 8 & $\mathrm{~F}$ & 57 & A & Face/neck/hands & 2 & 1 & 3 & 3 & 2 \\
\hline 9 & $\mathrm{~F}$ & 58 & A & Face/neck & 3 & 3 & 4 & 4 & 3 \\
\hline 10 & $\mathrm{~F}$ & 58 & A & Face/décolleté & 2 & 2 & 3 & 3 & 2 \\
\hline 11 & $\mathrm{~F}$ & 63 & A & Face/décolleté/hands & 1 & 1 & 3 & 2 & 2 \\
\hline 12 & $\mathrm{~F}$ & 65 & $\mathrm{~A}$ & Face/neck/hands & 4 & 3 & 5 & 4 & 3 \\
\hline 13 & M & 51 & A & Face/neck & 2 & 2 & 4 & 3 & 3 \\
\hline 14 & $\mathrm{~F}$ & 54 & A & Face/décolleté/hands & 3 & 2 & 3 & 2 & 2 \\
\hline 15 & $\mathrm{~F}$ & 53 & A & Face/décolleté/neck & 3 & 3 & 3 & 3 & 2 \\
\hline 16 & $\mathrm{~F}$ & 56 & A & Face/décolleté/hands & 3 & 3 & 4 & 4 & 3 \\
\hline 17 & $\mathrm{~F}$ & 57 & A & Face/décolleté & 2 & 2 & 3 & 3 & 2 \\
\hline 18 & $\mathrm{~F}$ & 62 & A & Face/neck/hands & 2 & 1 & 4 & 4 & 3 \\
\hline 19 & $\mathrm{~F}$ & 62 & $\mathrm{~A}$ & Face/décolleté/hands & 2 & 1 & 4 & 4 & 3 \\
\hline 20 & M & 64 & A & Face/neck & 1 & 1 & 5 & 4 & 4 \\
\hline 21 & $\mathrm{~F}$ & 61 & A & Face/décolleté & 3 & 2 & 5 & 5 & 4 \\
\hline 22 & $\mathrm{~F}$ & 58 & A & Face/décolleté/neck & 3 & 3 & 3 & 3 & 2 \\
\hline 23 & $\mathrm{~F}$ & 59 & A & Face/décolleté/neck & 2 & 2 & 3 & 3 & 2 \\
\hline 24 & $\mathrm{~F}$ & 54 & A & Face/neck/hands & 2 & 1 & 4 & 4 & 3 \\
\hline 25 & $\mathrm{~F}$ & 52 & A & Face/neck & 2 & 2 & 3 & 2 & 2 \\
\hline 26 & $\mathrm{~F}$ & 54 & A & Face/décolleté/neck & 4 & 3 & 4 & 4 & 3 \\
\hline 27 & $\mathrm{~F}$ & 64 & A & Face/décolleté/neck & 3 & 2 & 4 & 4 & 3 \\
\hline 28 & $\mathrm{~F}$ & 62 & A & Face/décolleté & 2 & 2 & 4 & 4 & 3 \\
\hline 29 & $\mathrm{~F}$ & 63 & A & Face/décolleté & 3 & 1 & 4 & 3 & 3 \\
\hline 30 & M & 61 & A & Face/neck & 3 & 1 & 3 & 3 & 2 \\
\hline 31 & $\mathrm{~F}$ & 60 & A & Face/décolleté/neck & 1 & 1 & 4 & 4 & 3 \\
\hline 32 & $\mathrm{~F}$ & 60 & A & Face/décolleté/neck & 3 & 2 & 3 & 2 & 2 \\
\hline 33 & $\mathrm{~F}$ & 37 & A & Face/décolleté/neck & 1 & 1 & 2 & 2 & 1 \\
\hline
\end{tabular}


Table 4 continued

\begin{tabular}{|c|c|c|c|c|c|c|c|c|c|}
\hline No. & Sex & Age (years) & Formulation used & Treatment site & GAIS1 & GAIS2 & WSRS0 & WSRS1 & WSRS2 \\
\hline 34 & $\mathrm{~F}$ & 38 & $\mathrm{~B}$ & Face/décolleté & 2 & 2 & 2 & 2 & 1 \\
\hline 35 & $\mathrm{M}$ & 43 & $\mathrm{~B}$ & Face/neck & 1 & 1 & 3 & 3 & 2 \\
\hline 36 & $\mathrm{~F}$ & 50 & $\mathrm{~B}$ & Face/décolleté & 2 & 2 & 4 & 3 & 3 \\
\hline 37 & $\mathrm{~F}$ & 36 & $\mathrm{~B}$ & Face/décolleté/neck & 1 & 1 & 2 & 1 & 1 \\
\hline 38 & $\mathrm{~F}$ & 35 & $\mathrm{~B}$ & Face/décolleté/neck & 1 & 1 & 3 & 1 & 1 \\
\hline 39 & $\mathrm{~F}$ & 47 & $\mathrm{~B}$ & Face/décolleté/neck & 3 & 2 & 3 & 3 & 2 \\
\hline 40 & $\mathrm{~F}$ & 42 & $\mathrm{~B}$ & Face/décolleté/neck & 2 & 2 & 3 & 3 & 2 \\
\hline 41 & $\mathrm{~F}$ & 47 & $\mathrm{~B}$ & Face/décolleté & 2 & 1 & 4 & 3 & 3 \\
\hline 42 & M & 39 & $\mathrm{~B}$ & Face/neck & 1 & 1 & 2 & 2 & 1 \\
\hline 43 & M & 40 & $\mathrm{~B}$ & Face/neck & 1 & 1 & 2 & 2 & 1 \\
\hline 44 & $\mathrm{~F}$ & 45 & $\mathrm{~B}$ & Face/décolleté & 2 & 2 & 3 & 2 & 2 \\
\hline 45 & $\mathrm{~F}$ & 43 & $\mathrm{~B}$ & Face/décolleté/neck & 1 & 1 & 3 & 2 & 2 \\
\hline 46 & $\mathrm{~F}$ & 39 & $\mathrm{~B}$ & Face/neck & 2 & 1 & 2 & 2 & 1 \\
\hline 47 & $\mathrm{~F}$ & 45 & $\mathrm{~B}$ & Face/décolleté/ & 1 & 1 & 4 & 4 & 3 \\
\hline 48 & $\mathrm{~F}$ & 35 & $\mathrm{~B}$ & Face/décolleté/neck & 2 & 2 & 3 & 2 & 1 \\
\hline 49 & $\mathrm{~F}$ & 36 & $\mathrm{~B}$ & Face/décolleté/neck & 3 & 2 & 2 & 1 & 1 \\
\hline 50 & $\mathrm{~F}$ & 49 & $\mathrm{~B}$ & Face/décolleté & 2 & 1 & 4 & 3 & 2 \\
\hline
\end{tabular}

GAIS1 after two treatments, GAIS2 after four treatments; significantly different from GAIS1 $(P=0.008)$, WSRSO at the beginning of the treatment, WSRS1 after two treatments; significantly different from WSRS0 $(P=0.014), W S R S 2$ after four treatments; significantly different from WSRS1 $(P=0.002)$

treatment $(P=0.014)$, and this significance was augmented after four treatments $(P=0.002)$. These data are summarized in Table 4 .

To further characterize the effects of the skin treatment, histological and immunohistochemical analysis of the skin of four patients treated with formulation A $(n=4)$ was performed at baseline and after 6 weeks. The histological analysis failed to show any significant difference at the level of the epithelium and of the dermis (data not shown). Conversely, immunohistochemical analysis revealed a decrease in IL-1 $\beta$, IL-6, and MMP-1, and an increase in Col-1. Figure 2 is a histogram depicting the different immunohistochemical expression levels of the four markers; these differences were statistically significant as depicted in the figure.

\section{DISCUSSION}

The primary factor that causes human skin aging is its direct contact with the environment; therefore, skin aging can be considered as a consequence of environmental damage. The most important environmental factor involved in human skin aging is ultraviolet (UV) irradiation from the sun. This sun-induced skin aging (photo-aging) depends primarily on 


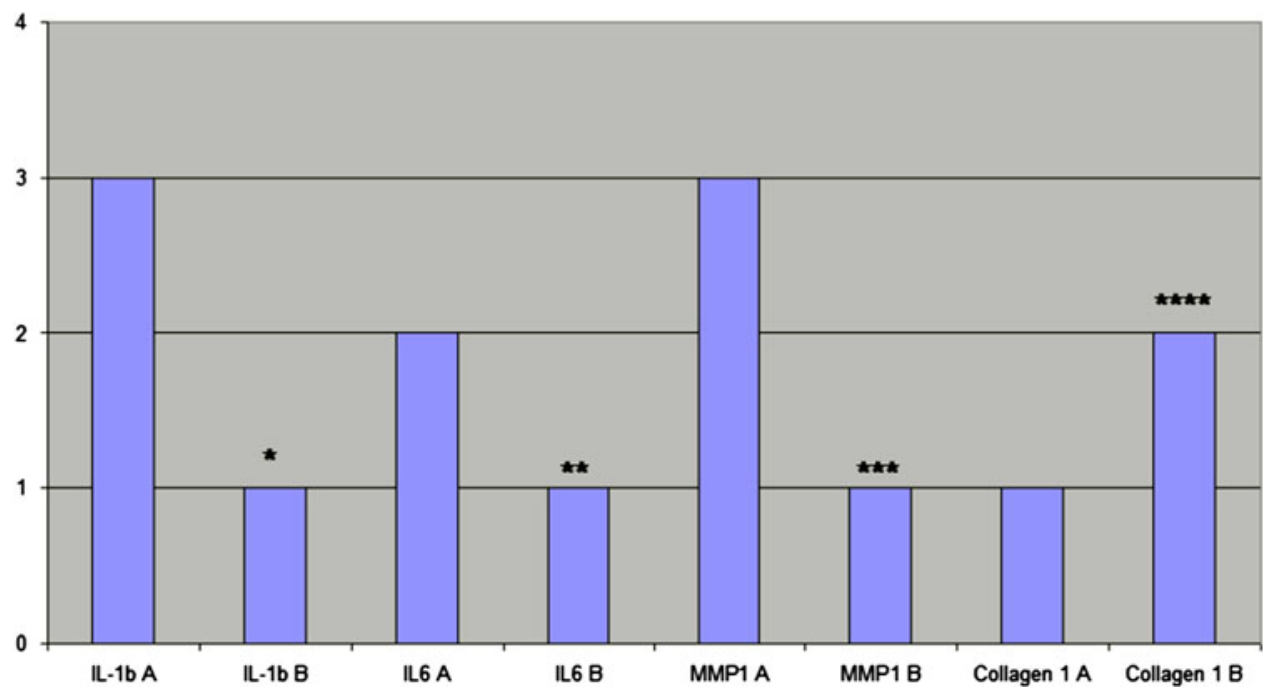

Fig. 2 Different expression levels of the various proteins analyzed, before (marked as $A$ ) and after (marked as $B$ ) treatment with formulation A. Asterisks indicate the

the degree of sun exposure and skin pigment. Individuals who have outdoor lifestyles and those who are lightly pigmented will experience the greatest degree of photo-aging [12]. The deleterious effects of solar radiation on the skin impact primarily on the dermal connective tissue with accelerated breakdown and synthesis of collagen, and enhanced inflammatory processes. These processes are directly responsible for the clinical appearance of photo-aged skin: wrinkling, telangiectasia, laxity, pigment changes, coarseness, dehydration, and loss of tensile strength [13]. The primary treatment of photo-aging is photoprotection, but secondary treatment could be achieved with the use of antioxidants, as reactive oxygen species (ROS) generated in the skin by UV-radiation (UVR) exposure are among the most important factors causing photo-aging [14]. In fact, antioxidants can regulate the transfer of electrons or quencher free radicals escaping from the electron transport chain. It has to be underlined, however, that no significant protective effect of "natural" and statistical significance of each expression level. ${ }^{*} P=0.002$; ${ }^{* *} P=0.011 ;{ }^{* * *} P=0.001 ;{ }^{* * *} P=0.0001$

synthetic antioxidant are detectable, when applied topically before UVR expose. Indeed, UVR-induced skin damage is a rapid event and antioxidants can prevent such damage when present at relevant concentrations at the site of the body exposed to UVR [15]. Nevertheless, molecular key and histochemical features underlying age-dependent phenotypic alterations of human skin include decreased collagen production in dermal fibroblasts, leading to the fragmentation and disarray of collagen fibrils in the dermis $[14,16]$. This structural disturbance results in various physiological consequences, including interference with the mechanical properties of skin and impairment of resident cell function in the dermis, resulting in disruption of the normal interaction of cells within the microenvironment of the extracellular matrix (ECM) [17].

The aim of mesotherapy for skin rejuvenation is maintenance and/or recovery of youthful skin. Mesotherapy increases the biosynthetic capacity of fibroblasts and the 
reconstruction of an optimal physiologic environment, the enhancement of cell activity, and the synthesis of collagen, elastin, and hyaluronic acid [18]. Currently applied medications employ microinjection of hyaluronic acid, vitamins, minerals, and amino acids into the superficial layer of the skin. It is generally assumed that many formulations used in mesotherapy improve the appearance of skin by increasing the biosynthetic capacity of human skin fibroblasts. Moreover, it has to be considered that exogenous antioxidants, such as vitamins C-E and many others, cannot be synthesized by the human body and must be obtained by the diet. Indeed, mesotherapy treatment can be an ideal solution to achieve optimal concentrations of these substances directly in the skin [19].

The wide range in the age of the participants enrolled in this study is justified by the differences in the two groups of patient treated: younger subjects (group 2) that present mild/moderate photo-aging and in which the treatment is preventive, and older patients (group 1) that present severe photoaging and in which the treatment is essentially therapeutic. The results produced were statistically analyzed, and treatment resulted in significant and long-lasting rejuvenation effects. These data were confirmed both subjectively and objectively by GAIS and WSRS score analysis.

In order to investigate the molecular effects on the skin caused by treatment with formulation $\mathrm{A}$, the authors analyzed the expression levels of IL-6, IL-1 $\beta$, MMP-1, and Col-1 at the beginning and at the end of the treatment using immunohistochemistry. The proteins tested were chosen as it has previously been demonstrated that their expression can be modified by topical antioxidant treatment of the skin [20]. Indeed, the authors observed a decrease in IL-1 $\beta$, IL-6, and MMP-1 and in increase in Col-1. The immunohistochemical results suggest, therefore, that treatment with formulation $\mathrm{A}$ is able to interfere with the effects on collagen production in damaged skin by increasing the expression of Col-1. Nevertheless, the downregulation of IL-1 $\beta$, IL-6, and MMP1 suggests a role for this formulation in interfering with the inflammatory processes. Therefore, the authors predict that this formulation will increase moisturization, elasticity, and luminosity, and has a restructuring action in the skin resulting in anti-aging processes in patients with severe photo-aging.

The authors assume for formulation B, enriched in antioxidant substances such as idebenone, an anti-aging role such as preventive anti-aging treatment, particularly for oxidative stress anti-aging (mild/moderate photo-aging). In general topical antioxidants exert their effects by downregulating freeradical-mediated pathways that damage skin [21]. A wide variety of antioxidant or other photo-chemicals have been reported to produce substantial skin photoprotective effects, but ubiquinone has been recently shown as one of the most effective [22]. Ubiquinone is an important lipophilic antioxidant synthesized by the body and critical for the protection of mitochondrial membranes [23]. Idebenone is a synthetic derivative [24]. Both molecules have been suggested as topical antioxidant ingredients for the protection of skin from oxidative damage. Idebenone was ranked the number one antioxidant in a recent clinical trial [25]. Consistent with these data, the present authors have demonstrated that this 
formulation with idebenone represents a promising and efficient treatment for photoaging aspects of patients aged 30-60 years.

The wide range in the age of the patients enrolled in this study is justified by the differences in the two groups of patient treated: younger subjects (group 2) that present mild/moderate photo-aging and in which the treatment is preventive and older patients (group 1) that present a severe photoaging and in which the treatment is essentially therapeutic. The data described in this paper suggest that mesotherapy is an effective and safe procedure for both preventive and therapeutic anti-aging. In fact, using different formulations, it is possible to achieve good subjective and objective results in two different cohorts of patients: younger patients, where the most important effect was on prevention of aging, and older patients, where the most relevant effect was a therapeutic action on aging. It is assumed that the therapeutic action of formulation A was due to substances able to restore the dermal architecture of the skin, whereas for formulation B, enriched in antioxidant substances such as idebenone, the action was mostly a preventive anti-aging role, particularly for oxidative stress.

Limitations of the study include the small number of patients enrolled and the short time of observation. Therefore, it cannot be excluded that part of the amelioration effectively registered could disappear after several months.

In conclusion, these new minimally invasive mesotherapy techniques, can improve the clinical appearance of the skin in different age groups, via action on the maintenance and/or restoration of healthy and youthful texture of skin, even if it has to be underlined that these results on the clinical appearance of the skin are not permanent and tend to diminish after a period of time.

\section{ACKNOWLEDGMENTS}

The work was supported by Second University grants to A.B. Alfonso Baldi is the guarantor for this article, and takes responsibility for the integrity of the work as a whole.

Conflict of interest. The authors have no conflicts of interest to declare.

Open Access. This article is distributed under the terms of the Creative Commons Attribution Noncommercial License which permits any noncommercial use, distribution, and reproduction in any medium, provided the original author(s) and the source are credited.

\section{REFERENCES}

1. Buck DW, Alam M, Kim JYS. Injectable fillers for facial rejuvenation: a review. J Plast Reconstr Aesth Surg. 2009;62:11-8.

2. Oringer JS, Kang S, Johnson TM, et al. Connective tissue remodeling induced by carbon dioxide laser resurfacing of photodamaged human skin. Arch Dermatol. 2004;140:1326-32.

3. Tan WQ, Gao ZJ, Xu JH, et al. Inhibiting scar formation in vitro and in vivo by adenovirusmediated mutant Smad4: a preliminary report. Exp Dermatol. 2011;20:119-24.

4. Pistor M. What is mesotherapy? Chin Dent Fr. 1976;46:59-60.

5. Galadari H, Al Faresi F. Mesotherapy. Skinmed 2011;9:342-3.

6. Lacarrubba F, Tedeschi A, Nardone B, et al. Mesotherapy for skin rejuvenation: assessment of the subepidermal low-echogenic band by ultrasound evaluation with cross-sectional B-mode scanning. Dermatol Ther. 2008;21(Suppl. 3):S1-5. 
7. Iorizzo M, De Padova MP, Tosti A. Biorejuvenation: theory and practice. Clin Dermatol. 2008;26: 177-81.

8. Tammi MI, Day AJ, Turley EA. Hyaluronan and homeostasis: a balancing act. J Bio Chem. 2002; 277:4581-4.

9. Yoneda M, Shimizu S, Nishi Y, et al. Hyaluronic acid-dependent change in the extracellular matrix of mouse dermal fibroblasts that is conducive to cell proliferation. J Cell Sci. 1988;90:275-86.

10. Gao F, Liu Y, He Y, et al. Hyaluronan oligosaccharides promote excisional wound healing through enhanced angiogenesis. Matrix Biol. 2010;29:107-16.

11. Greesin J C, Hendricks L J, Falkenstein PA, et al. Regulation of collagen synthesis by ascorbic acid: characterization of the role of ascorbate-stimulated lipid peroxidation. Arch Biochem Biophys. 1991; 290:127-32.

12. Fisher GJ, Kang S, Varani J, et al. Mechanisms of photoaging and chronological skin aging. Arch Dermatol. 2002;138:1462-70.

13. Kligman LH. Photoaging. Manifestations, prevention, and treatment. Clin Geriatr Med. 1989; $5: 235-51$.

14. West MD. The cellular and molecular biology of skin aging. Arch Dermatol. 1994;130:87-95.

15. Sjerobabski Masnec I, Poduje S. Photoaging. Coll Antropol. 2008;32:177-80.

16. Warren R, Gartstein V, Klingman A, Montagna W, Allendorf RA, Ridder GM. Age, sunlight, and facial skin: a histologic and quantitative study. J Am Acad Dermatol. 1991;25:751-60.

17. Varani J, Dame MK, Rittie L, et al. Decreased collagen production in chronologically aged skin: role of age-dependent alteration in fibroblast function and defective mechanical stimulation. Am J Pathol. 2006;186:1861-8.

18. Fisher A, Morley JE. Anti-aging and complementary therapies. In: Landefeld C, Palmer R, Johnson MA, Johnston C, Lyons W, editors. Current geriatric diagnosis and treatment. New York: Lange Medical Books/McGraw-Hill; 2004. p. 468-81.

19. Atiyeh BS, Ibrahim AE, Dibo SA. Cosmetic mesotherapy: between scientific evidence, science fiction, and lucrative business. Aesthet Plast Surg. 2008;32:842-9.

20. Mc Daniel DH, Neudecker BA, DiNardo JC, Lewis JA 2nd, Mailbach HI. Clinical efficacy assessment in photodamaged skin of $0.5 \%$ and $1.0 \%$ idebenone. J Cosmet Dermatol. 2005;4:167-73.

21. Kamel NS, Gammack J, Cepeda O, Flaherty JH. Antioxydants and hormones as antiaging terapies: high hopes, disappointing results. Cleve Clin J. 2006;73:1049-56.

22. Crane FL. Biochemical function of coenzymes Q10. J Am Coll Nutr. 2001;20:591-8.

23. Dallner G, Sinderlar PJ. Regulation of ubiquinone metabolism. Free Radic Biol Med. 2000;29:285-94.

24. Wieland E, Schutz E, Armstrong VW, Kuthe F, Heller C, Oellerich M. Idebenone protects hepatic microsomes against oxygen radical-mediated damage in organ preservation solutions. Transplantation. 1995;60:444-51.

25. McDaniel DH, Neudecker BA, DiNardo JC, Lewis JA 2nd. Maibach HI. Idebenone: a new antioxidantPart I. Relative assessment of oxidative stress protection capacity compared to commonly known antioxidants. J Cosmet Dermatol. 2005; $4: 10-7$. 